Mundo Revista de agrario
Mundo Agrario, abril 2018, vol. 19, n 40, e075. ISSN 1515-5994

Universidad Nacional de La Plata

Facultad de Humanidades y Ciencias de la Educación

Centro de Historia Argentina y Americana

\title{
Ricos buenos, pobres dignos. Moral y poder en una empresa agroexportadora del sur santafecino ${ }^{1}$
}

\author{
María Soledad Córdoba \\ Universidad Nacional de San Martín, Argentina \\ mariasolecordoba@gmail.com
}

Cita sugerida: Córdoba, M. S. (2018). Ricos buenos, pobres dignos. Moral y poder en una empresa agroexportadora del sur santafecinoMundo Agrario, 1940, e075.

https://doi.org/10.24215/15155994e075

Recibido: 13 de enero de 2017 - Aceptado: 12 de octubre de 2017 - Publicado: 26 de marzo de 2018

(c) (1) (2) Esta obra está bajo licencia Creative Commons Atribución-NoComercial-CompartirIgual 4.0 Internacional (c) ${ }_{\text {BY }}$ NC $_{\text {SA }} h$ http://creativecommons.org/licenses/by-nc-sa/4.0/deed.es_AR 


\section{Ricos buenos, pobres dignos. Moral y poder en una empresa agroexportadora del sur santafecino $^{1}$}

The noble rich and the worthy poor. Moral and power in an agro-export company in southern Santa Fe

María Soledad Córdoba

Universidad Nacional de San Martin, Argentina

mariasolecordoba@gmail.com

\section{RESUMEN:}

A partir de un trabajo de campo etnográfico realizado entre 2010 y 2012, este artículo aborda los mecanismos de gestión y disciplinamiento, tanto de la fuerza de trabajo como de la población rural de influencia, con los cuales una empresa agroexportadora nacional y sus dueños logran garantizarse una base social que sostiene y reproduce su posición de poder en el territorio a lo largo de más de 150 años de trayectoria. El estudio de la empresa y de la pequeña comuna rural santafecina, fundada por sus propietarios, reveló tres mecanismos principales de ejercicio del poder: la incorporación de los empleados en un sistema de relaciones de patronazgo, la creación y el control de instituciones comunitarias, y la implementación de "talleres de formación en valores" para empleados, sus esposas, docentes y otros empleados públicos. La caracterización de estos mecanismos permitirá restituir el modo de dominación de una élite rural contemporánea que, a partir de la institucionalización del par categorial rico-bueno / pobre-digno, ha sedimentado desigualdades persistentes a lo largo del tiempo.

Palabras Clave: Patronazgo, Trabajo rural, Desigualdad social persistente, Poder, Moral, Santa Fe.

\section{Abstract:}

Based on an ethnographic fieldwork carried out between 2010 and 2012, this paper deals with the mechanisms of management and discipline, both of the workforce and the rural population, with which a national agroexport company and its owners has managed to guarantee a social base that sustains and reproduces its position of power in the territory during more than 150 years of trajectory. The study of the company and the small rural commune of Santa Fe, founded by its owners, revealed three main mechanisms of exercise of power: the incorporation of the employees in a system of patronage relations, the establishment and control of Community institutions, and the implementation of "value training workshops" for employees, their wives, teachers and other public employees. The characterization of these mechanisms will explain the domination's mode of a contemporary rural elite who, with the institutionalization of the Noble-Rich / Worthy-Poor category, has established persistent inequalities over time.

KEYWORDs: Patronage, Rural employment, Persistent social inequality, Power, Moral, Santa Fe.

\section{INTRODUCCIÓN}

A partir de un trabajo de campo etnográfico realizado entre 2010 y 2012, que implicó la estadía en los territorios estudiados durante diferentes momentos, este artículo aborda los mecanismos y estrategias de gestión y disciplinamiento, tanto de la fuerza de trabajo como de la población rural de influencia, a partir de los cuales una empresa agroexportadora nacional ha logrado garantizarse una base social que sostiene y reproduce su posición de poder en el territorio, a lo largo de 150 años de trayectoria. La empresa estudiada posee 8.300 hectáreas de tierra de su propiedad, ubicadas en dos localidades al sur de las provincias de Córdoba y Santa Fe, en dos lotes de proporciones casi idénticas para cada provincia. Para este trabajo, focalizaremos el análisis del territorio ubicado en el sur de Santa Fe, zona pampeana. En el mencionado período se realizaron estadías de campo en la casa de una vecina del pueblo santafecino con quien se convivió durante un mes, y en las estancias de la familia en ambas provincias durante períodos cortos de tres días, que 
coincidieron con las ocasiones en las que se implementaban talleres de "formación en valores". Además de la observación participante, durante la investigación se realizaron, en total, 87 entrevistas semiestructuradas.

El estudio de la empresa -posicionada como una de las 48 más grandes de Argentina según Murmis y Murmis (2011)-, de las relaciones con sus empleados y con los habitantes de la pequeña comuna rural santafecina, fundada por estos empresarios sobre sus propias tierras, reveló tres mecanismos principales de ejercicio del poder: la incorporación de los empleados en un sistema de relaciones de patronazgo; la creación y el control de instituciones comunitarias como la escuela, el club social y deportivo, la biblioteca y una "comisión de seguridad" del pueblo, y la implementación de talleres de "formación en valores" con alto contenido moralizante, destinados a los empleados, sus esposas, docentes de escuelas y empleados de instituciones comunales.

Este trabajo presentará la caracterización de estos tres mecanismos, lo que permitirá restituir el modo de dominación de una élite rural contemporánea que reproduce "desigualdades persistentes" (Tilly, 2002), y que abarca al conjunto de los habitantes del territorio estudiado.

Los actores, la empresa y el pueblo rural en el que se llevó a cabo la investigación han sido rebautizados.

\section{LA CONFORMACIÓN DE UN PUEBLO, EL ASENTAMIENTO DE UNA FAMILIA Y LOS DEVENIRES DE UNA EMPRESA}

Ubicado en el sur santafecino, Pueblo Sanandrés no contaba, para el momento en que se llevó a cabo la investigación, con medios de transporte públicos que permitieran llegar hasta allí. El pueblo comprendía un área total urbanizada de unos $2 \mathrm{~km} 2$ : la mayor parte de la población se ubicaba a la derecha y a lo largo de una avenida principal que conectaba, por un extremo, la ruta provincial que lleva a Rosario y, por el otro, la planta de silos de Agropecuaria Sanandrés. Alrededor del pequeño caserío todo eran campos cultivados. En los meses de enero y febrero sólo se observaban plantaciones de soja que comenzaban a pocos metros de los jardines y de las ventanas de las casas. Salvo el jefe de la comuna, el médico del pueblo y el dueño de una fábrica de muebles, ningún vecino mencionó eventuales problemas o impactos en la salud ligados a la inhalación de agroquímicos o del polvillo de cereal.

La historia del pueblo está estrechamente ligada a la historia de la familia y de la empresa Sanandrés. La familia, todavía radicada en España, adquirió un primer lote de 540 hectáreas en el sur santafecino que comenzó a ser explotado en 1857, cuando uno de sus miembros decidió cruzar el océano e iniciar una actividad pecuaria. Para 1870, la familia había extendido su propiedad a 5.000 hectáreas, de modo que -de acuerdo a la clasificación de Pucciarelli (1986) para las explotaciones entre fines de S. XIX y principios de S. XX- la actividad se encuadraba ya desde sus inicios como empresa capitalista en el sector agropecuario ${ }^{2}$. En 1930, con la adquisición de otro campo en la provincia de Córdoba, consolidó una propiedad de 8.300 hectáreas de tierra en total que conserva hasta la actualidad.

En los primeros 50 años de la empresa se dedicaron a la cría de ovejas, en consonancia con el boom del lanar (Barsky y Gelman, 2009; Hora, 2010), por lo que el establecimiento constituía una "estancia ovina o sheep farm" (Sabato, 1989). A principios del siglo XX, el ganado ovino fue reemplazado por el vacuno y desde los años 30, debido a la extensión de la agricultura, pasaron unos 40 años como rentistas obteniendo beneficios sin mayores esfuerzos productivos, tal como sostiene la bibliografía (Hora, 2005a, p. 39 y 2005b, p. 317). También en línea con la literatura especializada (por ejemplo Barsky y Gelman, 2009, p. 196), los campos de la empresa fueron arrendados a colonos venidos de Europa, en su mayoría italianos, quienes pagaban alrededor del $42 \%$ de la cosecha por el arriendo. En aquel entonces, se cultivaba lino, maíz, alfalfa y papa. Si seguimos a Balsa (2006, p. 42), podemos afirmar que Agropecuaria Sanandrés funcionó como una estancia mixta desde los años 20-30 hasta los años 60, subordinando la agricultura, desarrollada por arrendatarios y aparceros, a la actividad ganadera, controlada directamente por los miembros de la familia Sanandrés. 
Desde principios de Siglo XX, toda la superficie que hoy corresponde al distrito se encontraba régimen de propiedad, por lo tanto, el poblamiento dependía de la disponibilidad de los dueños de la tierra para vender, alquilar o ceder terrenos para edificar. Un primer asentamiento se conformó en el noreste del actual trazado urbano a partir del loteo de terrenos pertenecientes a otra familia que se retiraría del territorio en la década del 90. Al mismo tiempo, hacia el sur, se formó un segundo asentamiento sobre terrenos cedidos por la familia Sanandrés para la instalación de la estación ferroviaria, la escuela y un almacén de ramos generales y acopio de granos. La familia propuso a uno de sus peones hacerse cargo de esta actividad comercial que concentró la venta de la producción completa de la estancia por varias décadas. La imposición de comprar insumos y vender la producción en un lugar determinado por el dueño de la tierra -que funcionaba también como control de precios-, sumada al elevado costo del arriendo (en relación a la producción), resultaba en las escasas y controladas posibilidades que tenían los inmigrantes arrendatarios de acumular excedentes $\mathrm{y}$, por lo tanto, de adquirir bienes como terrenos o ganado a los fines de establecerse en el territorio. Esta exclusión del inmigrante de la propiedad de la tierra para el territorio estudiado se encuentra en continuidad con lo sostenido en la "interpretación tradicional" de la historiografía para la expansión agrícola de la zona pampeana (Scobie, 1968; Miguez, 1986, pp. 97-101; Volkind, 2010, p. 29; Pucciarelli, 1996, p. 33).

A partir de fines de los años 50 y 60 la empresa comenzó paulatinamente a retomar el control sobre la actividad productiva y sobre la tierra. Este proceso se desarrolló a través de tres modalidades diferentes: el desalojo de colonos mediante indemnización, la venta de la tierra para los colonos que trabajaban superficies inferiores a 90 hectáreas, y la titulación directa (cesión) de 30 hectáreas para los colonos que trabajaban superficies mayores a 90 has. La familia privilegió el desalojo por indemnización, mientras que la venta o la cesión de la tierra se concretaron en un número insignificante de casos.

Durante este proceso, de expulsión de algunos colonos y de asentamiento definitivo para otros, la familia loteó los terrenos que separaban -por unos 500 a 600 metros- al asentamiento inicial en el noroeste del constituido en torno a la estación de ferrocarril en el sur. A partir de esta unificación, en 1965 quedó fundado Pueblo Sanandrés. En esos terrenos unificantes se construyeron la iglesia, el edificio comunal y, posteriormente, la plaza principal del pueblo. A fines de los años 60 finalizó el proceso de descolonización y la actividad económica de la empresa comenzó a orientarse hacia el procesamiento de semillas. De acuerdo al relato de un excolono, para ese tiempo quedó un reducido número de agricultores elegidos por la familia:

Allá por el año 60, hubo un alboroto de un grupo de colonos que empezaron a viajar a Rosario con frecuencia a visitar a
Federación Agraria para expropiar el campo a los Sanandrés, eran 8 o 9 revolucionarios y querían que mi padre fuera también.
Pero él siempre tenía una respuesta: "el campo no es mío, cuando lo tenga que entregar lo entrego, el dueño es el dueño”.
Todo eso le llegó al tío de Pedro [actual presidente de la empresa], entonces cuando vendieron el campo en el año 65 a mí me
dieron prioridad de comprar lo que yo trabajaba que eran 40 has, más lo de un vecino que eran 30 has, cuando a los demás, si
los podían sacar con una mano atrás y otra adelante, ¡los sacaban! (...) En este sector del campo, solamente esta franja pegada
al pueblo, éramos 28 colonos y solamente a tres se nos vendió [Entrevista 31/01/2012].

Durante los años 80 se distribuyeron los lotes más céntricos entre los cuadros de la empresa, quienes en aquellos años estaban constituyendo sus familias. Todos ellos continuaban en 2012 trabajando para la firma en puestos claves: gerente administrativo y de finanzas, apoderado (antes gerente comercial) y gerente de producción. La misma operación, pero en la forma de alquiler o de préstamo de viviendas, se repitió para los dos encargados de las plantas de silos y de procesos de semillas, quienes se trasladaron al pueblo por motivos laborales. En sus testimonios, estos cuadros dieron cuenta de la ayuda recibida por parte de los dueños de la empresa ante la necesidad de una vivienda, en un momento clave de sus vidas como el de la constitución de una familia.

A partir de los años 90 y 2000, la familia Sanandrés posibilitó además la compra de terrenos en los márgenes de la urbanización por parte de algunos de sus trabajadores menos calificados pero con antigüedad en la empresa y familia a cargo, y descontaba el pago por la compra de la tierra en cuotas directamente de la remuneración mensual. De esta manera, los dueños de la tierra habían diseñado un restringido espacio 
urbano, ubicando en el centro los edificios de las instituciones y las viviendas de los cuadros (gerentes y empleados más calificados), y en los márgenes las viviendas de los peones. Los trabajadores "golondrina" se hospedaban en viviendas colectivas acondicionadas exclusivamente para esta finalidad. Durante la realización del trabajo de campo en Pueblo Sanandrés, en enero de 2012, vivían 6 peones oriundos de Santiago del Estero en la casa colectiva. Estos trabajadores, contratados por campaña (dos o tres meses) una o dos veces al año, eran presentados por quienes ya trabajaban en la empresa. Si con el pasar de los años continuaban empleados, habían formado una familia y tenían intenciones de establecerse de manera definitiva en el pueblo emprendían la difícil tarea de encontrar una vivienda en alquiler o de comprar un terreno para la construcción de la casa familiar.

La posesión de la tierra por parte de la familia y la ausencia de terrenos fiscales reconfiguraba las políticas nacionales y provinciales de acceso a créditos para la vivienda. En efecto, como relataba un miembro de la Junta Comunal de 1983 a 2002, durante la gestión de Pedro Sanandrés (1983-1997), quien ya en ese momento era presidente de la homónima empresa, la Junta decidió que otorgaría dichas facilidades según un criterio de continuidad generacional:

Pedro tuvo una política muy importante, muy inteligente. Cuando él entró a la Comuna en 1983 dijo: "No pidamos casas
si no sabemos a quién se las vamos a dar. Pensemos que las casas sean para quienes vienen de una o dos generaciones de
conocerse en el pueblo", cosa que en otros pueblos si le ofrecían 10, le pedían 15 casas, porque eran 15 familias que venían de
otra provincia, entonces el día de las elecciones ése era un votito seguro. A Pedro no le importó el voto, sino la continuidad de
una generación conocida. (...) Siempre hemos tenido el cuidado de que la gente tuviese antecedentes de origen de familia (...),
que el papá y el abuelo y el bisabuelo hubiesen sido arrendatarios de los Sanandrés y que tuviesen el mejor de los conceptos
[Entrevista 31/01/12].

Desde hace al menos cuatro décadas la población se mantiene estable entre 800 y 1.000 habitantes; según los datos del Censo Nacional, la población alcanzaba 856 habitantes en 2010. El número de nacimientos es muy bajo y los jóvenes emigran a las grandes ciudades en busca de oportunidades laborales.

Desde la llegada de la familia al sur santafecino se sucedieron seis generaciones con numerosa descendencia que permanecieron ligadas a la propiedad de una porción de tierra cada vez más pequeña. La imposibilidad de incrementar la extensión de la propiedad y el incremento exponencial de los herederos con expectativa de obtener una ganancia por la misma impuso paulatinamente la necesidad de aumentar la renta a partir de una reorganización de la actividad productiva y del esquema de negocios. Por otra parte, la baja de la rentabilidad de las explotaciones agrícolas que conllevaron las políticas estatales desregulatorias de la década de los noventa (Azcuy Ameghino, 2000; Flammini, 2001; Barsky y Gelman, 2009) impactó en Agropecuaria Sanandrés de manera tal que una parte de la familia vendió el $35 \%$ de las acciones a la megaempresa Cresud, única empresa de capitales nacionales que cotiza en el Nasdaq.

Con el desafío de aumentar la rentabilidad, Agropecuaria Sanandrés adoptó el modelo de agronegocios a partir de los años noventa. En este proceso de transformación hubo dos factores determinantes: uno, la introducción de las "innovaciones" que constituyen el pilar tecnológico del modelo de agronegocios, más específicamente, la introducción de la tecnología en la siembra directa que "estabilizó los suelos y optimizó el uso del agua" y la aparición de la soja transgénica que "resolvió el problema de las malezas" (Gerente general y miembros de la familia Sanandrés, entrevista 27/04/2010), lo cual conllevó el aumento de la producción y las ganancias. El otro factor fue la tercerización de los procesos de la actividad agroproductiva (siembra, pulverización, cosecha, etc.), que produjo la venta del parque de maquinarias (18 tractores más máquinas para labranza convencional) y la reducción de un $60 \%$ de la mano de obra en relación de dependencia (Gerente de producción de Santa Fe y miembro de la familia Sanandrés, entrevista 28/04/2010).

La sociedad con una empresa transnacional como Cresud y la inserción de Agropecuaria Sanandrés en la red de instituciones técnicas como AAPRESID, AACREA o Fundación Producir Conservando, instituciones que se constituyeron como la punta de lanza de la inserción del modelo de agronegocios en Argentina (Gras y Hernández, 2016), transformaron el perfil de la actividad agrícola de una matriz 
empresarial familiar al horizonte globalizado de los agronegocios. Estas conexiones fueron claves en dicha transición y en el incremento de la rentabilidad de la empresa.

Luego de adoptar exitosamente el modelo organizacional y productivo de los agronegocios, Agropecuaria Sanandrés se especializó en la producción, el procesamiento y la comercialización de productos para exportación, commodities (soja, trigo y maíz) y specialities (arvejas, garbanzos y maíz pisingallo), trabajando en dichos cultivos con un sistema de rotación que amplía la cantidad de hectáreas trabajadas a 13.000. En los últimos diez años comenzó a comercializar la producción de terceros y finalmente logró insertarse a nivel regional en Uruguay, con la constitución, en 2011, de la primera sucursal en el extranjero para la comercialización de productos especiales con la marca Sanandrés. Los ingresos anuales alcanzaban, en junio de 2011, a 68 millones de pesos (cerca de 16 millones y medio de dólares, según la cotización del 15 de ese mes) -provenientes de la exportación a 50 países del mundo-, de los cuales el $60 \%$ correspondía a la venta de commodities y el $40 \%$ a la de productos especiales.

En 2012, la empresa poseía una planta de 20 silos y una de procesos ubicada en la sede santafecina. La última planta de 10 silos, inaugurada en 2011, fue montada con la última tecnología en proceso de granos, completamente informatizada. En su conjunto, la planta tiene una capacidad de almacenaje de 24.000 toneladas y una capacidad de proceso de granos de 100 toneladas por día. Según las características de la campaña, trabajan como máximo unas 80 personas en ambos campos. En períodos de actividad normal como los que observé, el número de empleados no superaba los 26 para cada estancia (incluyendo gerentes, personal administrativo, maestranzas, peones rurales, personal de cocina y de seguridad).

\section{LOS MECANISMOS DE EJERCICIO DEL PODER}

\section{Las relaciones de patronazgo}

En todas las ocasiones que visité las instalaciones de la empresa, la planta de silos estaba limpia, aireada y los doce peones que trabajaban allí no parecían preocupados ni estresados. Antes de decir cualquier otra cosa, cuando les preguntaba cómo era trabajar allí explicaban que estaban "en blanco", regularmente asegurados y declarados impositivamente. Se demostraban satisfechos por cómo eran tratados y por las condiciones de trabajo.

La investigación reveló diferentes modalidades de contratación/remuneración: el pago a destajo (por bolsa de cereal estibado), el jornal y el "fijo mensual". Esta última, si bien garantizaba un ingreso fijo mensual no implicaba una modalidad de contratación a las dependencias de la empresa, por el contrario, la totalidad de los peones interpelados se encontraban contratados por empresas tercerizadoras de mano de obra ${ }^{3}$. Sin embargo, pasar de una modalidad a otra no parecía remitir a las características de un trabajo por ciclos o temporadas (“campañas"). El pasaje a la modalidad "fijo mensual” requería muchos años de antigüedad (desde 6 hasta 15 años según los testimonios) y la capacidad y disponibilidad para asumir responsabilidades en el manejo de máquinas de mayor complejidad. El sueldo (entre 4.000 y 5.000 pesos, 924 y 1155 dólares en enero de 2012) no difería sustancialmente de un estibador de bolsas de cereal que trabajaba todos los días, pero sí garantizaba una regularidad en el ingreso y tareas más livianas que no requerían "andar haciendo fuerza, hombreando bolsas” de hasta $50 \mathrm{~kg}$ (Peón, entrevista15/01/2012). El hecho de que los mismos jornaleros y los estibadores conservaran esa modalidad de contratación por períodos muy prolongados de tiempo -hasta 15 años- no representaba un problema para ellos. Incluso, en algunos casos, esta modalidad era preferida por los mismos peones, quienes podían así "volver al pago" y quedarse con su familia por algunos meses. Dado que, en el caso de quedar "fijo mensual", las posibilidades de viajar hasta el norte del país eran escasas y supeditadas a la demanda de trabajo. 
La semana de trabajo era de seis días (de lunes a sábados) y el horario de 7:30 a las 18 horas, con una pausa para almorzar. Sin embargo, en momentos en que la demanda de exportación aumentaba, los peones debían garantizar su permanencia en el puesto de trabajo sin descanso semanal. Antes de mi última estadía en el pueblo, los peones habían trabajado durante tres meses sin descanso semanal, con horarios rotativos y sin pausa para almorzar; llegaban incluso a extender la jornada laboral hasta a doce horas diarias. Tal como me señalaron varios peones y algunas de sus esposas, así como también el encargado de la planta, esta situación no representaba un problema para ellos.

Por su parte, para las mujeres que realizaban tareas manuales en la estancia, como la preparación de comidas y la limpieza de las casas (madre e hija, quienes trabajaban en la estancia desde hacía dieciséis y seis años respectivamente), el régimen de contratación seguía la misma lógica: pasaban años con la modalidad de cobro por jornal y en las temporadas de mayor actividad tenían que estar disponibles los siete días de la semana desde las 7:30 a las 22 hs. durante uno o dos meses enteros.

La presión sobre la fuerza de trabajo se ejercía aparentemente en ausencia de conflicto, dado que, como ellos mismos afirmaban, se les "pagaba más”, de acuerdo al esfuerzo suplementario que se les pedía, y la familia Sanandrés les merecía el mayor de los respetos -se los calificaba como "muy buenos"o"excelentes patrones"-, de acuerdo a los testimonios recogidos en la totalidad de las entrevistas realizadas.

La convivencia prolongada en el pueblo y la interacción con sus habitantes permitieron indagar sobre las condiciones socioeconómicas de proveniencia de los trabajadores y las distintas modalidades a través de las cuales ahora se encontraban en dependencia con la empresa, en el marco de un sistema de dominación/ subordinación que abarcaba la comunidad rural en su conjunto y que explica la percepción de los trabajadores de su universo social y laboral. La investigación reveló que el reclutamiento de la mano de obra se realizaba en Añatuya -y áreas rurales circundantes-, capital del departamento General Taboada, sudeste de Santiago del Estero: ocho de los diez peones entrevistados en los distintos momentos del estudio, así como la cocinera de la estancia resultaron oriundos de la misma zona de Santiago. El reclutamiento era realizado de manera directa por los mismos empleados, sin mediación de empresas tercerizadoras u otros actores con base en territorio santiagueño como los "planilleros" (Mastrangelo y Deambrosi, 2011; Deambrosi, 2012). Características como la resistencia física, el disciplinamiento y la ausencia de conflicto entre trabajadores provenientes de Santiago del Estero han sido evidenciadas en investigaciones precedentes, tal como se muestra en Mastrangelo y Deambrosi (2011, p. 236) y Deambrosi (2012, p. 136).

En todos los relatos sobre sus condiciones de vida pasada (para aquellos que ya estaban instalados en Pueblo Sanandrés) o presente (para aquellos peones “golondrina”) se encontraban los mismos elementos de un contexto de agricultura de subsistencia en el lugar de origen: minifundios de alrededor de 50 hectáreas, de los que dependían núcleos familiares numerosos, actividades como la cría de animales, el cultivo de algunas hortalizas y algodón. La escasa demanda de mano de obra o la decisión de vender la tierra, obligaba a los hombres o a la familia completa a trasladarse en busca de empleo. La literatura especializada y los datos estadísticos nacionales confirman que Santiago del Estero posee uno de los índices de precarización laboral más altos del país. Según el informe de la Dirección Nacional de Relaciones Económicas con las Provincias (Ministerio de Economía de la Nación), elaborado a partir de los datos censales de 2010 y de la EPH del INDEC 2012, Santiago del Estero es la provincia con menor tasa de actividad laboral. En cuanto al grado de informalidad del empleo, los datos indican que Santiago del Estero es la segunda provincia, luego de Chaco, con mayor informalidad del país. Asimismo, representa la provincia que más trabajadores migrantes provee a las zonas agroproductivas núcleo de Argentina (cf. Tasso y Zurita, 2013; Neiman, 2009; Quaranta y Blanco, 2012; Desalvo, 2013).

En condiciones climáticas en que las temperaturas superan los 40 grados, el esfuerzo físico necesario para trabajar a la intemperie resulta extremo, sin contar que la falta de agua es un denominador común de la zona, y para abastecerse es necesario desplazarse hasta quince kilómetros. A una restringida demanda de mano obra (limpieza de montes para su conversión a la agricultura, limpieza de caminos, producción carbonera 
y ladrillera) se suma el riesgo físico de estos trabajos: en la producción de carbón, por ejemplo, abundan los testimonios sobre trabajadores que caen dentro de las fosas carboneras o que sufren intoxicaciones por inhalación de monóxido de carbono. Las condiciones laborales en el lugar de origen funcionaban, así, como una forma de disciplinamiento que obturaba los cuestionamientos sobre las condiciones de vida en un pueblo expuesto a las fumigaciones de manera permanente. De este modo, la mujer de un peón rural contrastaba la oferta de trabajo generada por la actividad agrícola con la calidad de vida del pueblo vinculada a los efectos de los agroquímicos, sobre los que dice no saber:

\begin{abstract}
Ahora hay chicos de otros pueblos que vienen a preguntar por trabajo en la estancia. (...) La estancia, dentro de todo, es algo relindo porque hay un montón de gente que trabaja ahí, gracias a ellos están todos los que están acá. Bueno, hay agroquímicos, qué sé yo, pero no es tanto como la estancia. La gente se sorprende porque pasan los camiones o los containers, pasan veinte camiones, van y vienen [pero] igracias a dios tenemos algo que pueden trabajar los chicos! (...) Drogas y delincuencia no hay, chicos en la calle que viven en la calle o criaturitas que andan desnudas tampoco (...) Acá estamos en otro mundo, vivimos en la gloria [Entrevista 17/01/2012].
\end{abstract}

Los salarios de los empleados en las tareas manuales (peones, personal de limpieza y cocina, personal de seguridad, etc.), ajustados a las necesidades de vida, limitaban su capacidad de ahorro, y los dejaban desprotegidos ante adversidades como problemas de salud $\mathrm{u}$ otros imprevistos. Ya señalamos cómo, durante los años 80, los empleados calificados (cuadros intermedios) habían acudido al patrón para conseguir comprar un terreno en el pueblo y luego para costear la construcción de la casa. Por su parte, los recursos que los peones ponían en juego para afrontar el financiamiento de estudios de algún miembro de la familia, pagar una intervención quirúrgica o conseguir una vivienda, pusieron en evidencia un sistema de relaciones asimétricas de intercambios y dependencia entre los empleados y la familia Sanandrés. De acuerdo a la literatura, este tipo de relaciones ha sido denominado como clientelismo o también patronazgo. Ambas categorías tienen como objeto estudiar relaciones personales entre individuos de desigual status social (Garriga Zucal, 2005, p. 6). De acuerdo a la literatura, las relaciones clientelares son entendidas como "el intercambio personalizado entre masas y elites de favores, bienes y servicios por apoyo político y votos" (Auyero, 2004, p. 21), razón por la cual el clientelismo es considerado tanto un "fenómemo político" como una "etiqueta moral", dado que, con su existencia, descalificaría cierto ideal de ciudadanía democrática (Vommaro y Combes, 2016, pp. 17-21). En ese sentido, es concebido como "un mal que debe combatirse", como "moralmente malo" (p. 131). Por su parte, las relaciones de patronazgo han sido caracterizadas por cuatro rasgos principales: la asimetría de poder entre las partes, el intercambio como sistema relacional no restringido al ámbito político, la duración en el tiempo del sistema de intercambios, la constitución afectiva de la relación que pone en juego valores como la lealtad, el respeto y el honor de las partes ( $c f$. Gellner, 1985; Scott, 1985; Moreno Luzón, 1994; Garriga Zucal, 2005).

Dado que el análisis no se reduce a relaciones patrón-cliente en el ámbito político, resulta más adecuado aquí hablar de patronazgo, antes que de clientelismo. El patronazgo puede definirse de forma muy genérica como una forma de poder y como el "clima moral" (Gellner, 1985, p. 12) en un determinado grupo social. De estas relaciones se destaca tanto una dimensión instrumental como una dimensión afectiva (Wolf, 1966), dado que "lo afectivo establece sólidos lazos entre las partes, originando relaciones que duran más allá del intercambio ocasional de bienes" (p. 22).

¿Cómo se materializaban las relaciones de patronazgo en el seno de Agropecuaria Sanandrés? En la investigación realizada, la totalidad de los trabajadores entrevistados manifestaron con seguridad que ante un problema personal o ante la necesidad de una ayuda económica pidieron hablar con el presidente de la empresa, quien "siempre" atendió a sus demandas. De acuerdo a la jerarquía del empleado, la audiencia se solicitaba directamente (cuadros o empleados calificados) o a través de los encargados o supervisores de tareas (peones), quienes previamente le planteaban la cuestión al presidente de la empresa. El sistema de ayudas económicas por fuera del salario implicaba así un comportamiento previo adecuado que abriera la posibilidad 
de la solicitud. Citemos dos ejemplos para ilustrar estos mecanismos: un empleado de la planta de silos, oriundo de Santiago del Estero y establecido en Sanandrés desde 2006 explicaba:

Me llamó Pedro a su escritorio y me dijo "no hay ningún problema, yo te voy a ayudar con 300 pesos, porque para la empresa vos ponés buena firma, todos te queremos, todos los encargados hablan bien de vos, que te portás muy bien, jamás faltaste el respeto a nadie, hacés lo que te dicen, nunca has mostrado mala cara”. Ahora me está ayudando a pagar. [Después] me dijo que él iba a hablar con el intendente para que me den una casa [propia] por parte de él [Entrevista 15/01/2016].

Otro peón oriundo de Chaco, segunda generación de trabajadores en la empresa (el padre y todos sus hermanos habían trabajado en Agropecuaria Sanandrés o continuaban haciéndolo), con quince años de antigüedad, relató un problema de salud que requería una intervención de urgencia, y daba por hecho que "la empresa" le facilitaría el dinero necesario para pagar los gastos de la operación que le realizarían al día siguiente. En contrapartida, el empleado debía tomarse sus vacaciones anuales para realizarse la operación:

Peón: Mañana me operan de cálculo en la vesícula, en Rosario. Me tomo un mes de vacaciones.

MSC: ¿Y por qué no te tomás por enfermedad?

Peón: Porque ya arreglamos así, la otra semana estuve tres semanas [por enfermedad] y me necesitan en la planta. El doctor me dio [las 3 semanas] porque no podía andar trabajando, tenía dolor y estuve internado de jueves a domingo. Ahí me enteré que tenía inflamada la vesícula y me programaron la cirugía. (...)

MSC: ¿YY te cubre la obra social?

Peón: La mitad, porque tengo que pagar un plus a los doctores. (...)

Esposa del peón: Y encima no juntamos toda la plata y mañana ya lo operan...

MSC: ¿Y cómo vas a hacer?

Peón: Voy a llamar a la empresa y le voy a decir que me manden plata [Entrevista 22/01/2012].

Además de facilitar ayudas económicas ante imprevistos de salud, tema que se repite en un número significativo de entrevistas realizadas a los empleados de todos los rangos, el actor económico también aparecía en sus relatos financiando estudios terciarios (para peones jóvenes con secundario completo o hijos de empleados) o universitarios (para hijos de cuadros).

Para el grupo materialmente desfavorecido que percibe una renta de subsistencia, con escasa o nula capacidad de ahorro, quedar excluido de este sistema de relaciones sociales y económicas conllevaba la pérdida de los beneficios sociales determinados por las relaciones de patronazgo o hasta incluso la pérdida de su fuente de trabajo, por lo que debía regresar a su lugar de origen donde se reencontraría con condiciones laborales aún más precarizadas.

Pero si las obligaciones estrictamente laborales (el pago de los salarios, la autorización de licencias, etc.) eran trascendidas por el actor económico con ayudas, financiamiento u otro tipo de dones, los empleados debían corresponderlos "dedicándole su vida", como testimonia la esposa del gerente administrativo:

Cuando estábamos en una etapa que fue fea, en el sentido que estábamos agotados, ellos nos decían "necesitan vacaciones" y nosotros decíamos "necesitamos trabajar" y nos mandaban cinco días a Córdoba. [Mi marido] es muy perseverante, muy correcto, muy derecho, entonces nosotros nos brindamos y ellos nos abrieron las puertas. Entonces es como que les debés la vida [Entrevista 20/01/2012].

El acto de pedir, como base de un endeudamiento en el que "se juega la vida" de las personas, constituye material y concretamente el acto de la subordinación a un orden social, económico y moral. Al orden social porque los empleados aceptaban su posición en una jerarquía social (incluso materializada en la arquitectura del espacio urbano), al orden económico porque no podían exigir aumentos de salario (tal como revelaron distintos testimonios, nunca se concedían aumentos, ni siquiera a los cuadros), y al orden moral porque la protección social que derivaba del sistema de obligaciones era resignificada en términos morales. Así, los dueños de la empresa responden a las necesidades de sus dependientes no porque generan un excedente de riqueza o porque constituye un derecho gozar de licencia en caso de enfermedad, sino porque son buenas personas, nobles, atentos, bondadosos. Por su parte, los empleados deben poder responder igualmente, de 
manera que faltar a la obligación debida es "es lo peor que te puede pasar, es fallar como persona”, como señalaba la responsable de calidad de la empresa (Entrevista, 14/01/2012).

Como veremos a continuación, esta lógica relacional material y simbólica ni es gratuita ni se limita a las relaciones laborales, sino que alcanza las instituciones públicas como la escuela, la comuna, la biblioteca y la policía.

\section{LA CREACIÓN Y CONTROL DE LAS INSTITUCIONES COMUNITARIAS}

La primera institución creada por la familia Sanandrés fue la escuela primaria pública en 1918. La familia cedió el terreno, financió la construcción del edificio escolar y tramitó la habilitación en la provincia. Aunque inicialmente la familia cobraba un alquiler a la cooperadora de la escuela por el usufructo del edificio, en 1982, el actual presidente de Agropecuaria Sanandrés, entonces presidente de la cooperadora escolar, donó el edificio al Ministerio de Educación provincial y dejó de percibir una renta por el mismo. En 2012, los profesores de informática y de inglés de la escuela pública del pueblo eran pagados total o parcialmente con contribuciones realizadas por la empresa.

En 1922, poco tiempo después de la inauguración de la escuela, la familia vendió los terrenos para la instalación del primer campo deportivo y la sede social del Sanandrés Football Club que se construyó con dinero de los socios. La familia eligió los colores que identificarían al equipo y donó los primeros conjuntos deportivos a los jugadores.

Con el retorno de la democracia en el país, Pedro Sanandrés, el actual presidente de la empresa, fue candidato a presidente de la Junta Comunal por el partido de la UCR. No sólo él ganó esas primeras elecciones, sino que fue sucedido por su compañero de fórmula y, posteriormente, por otros miembros de la misma agrupación, en un mecanismo de rotación cada dos años desde 1983 hasta 2003. Durante esos 20 años Pedro Sanandrés tuvo un rol directo en la toma de decisiones relativas al territorio, como presidente de la Comuna, como miembro de la Junta Comunal o como controlador de cuentas. Durante su gestión como presidente encabezó una comisión para refundar la biblioteca que había funcionado durante pocos años, entre 1946 y 1950. En 2012, mientras la Comuna aportaba 350 pesos ( 81 dólares al 16/01/2012) mensuales, Agropecuaria Sanandrés contribuía con la suma de 500 pesos (115,5 dólares) por mes para el mantenimiento de la biblioteca.

Por último, la familia colaboró activamente en la creación de una “comisión de seguridad”, surgida en 2006 a raíz de un robo a mano armada ocurrido en la casa de un ingeniero agrónomo. Este hecho provocó una gran conmoción en un pueblo "donde nunca pasa nada", tal como refieren numerosas entrevistas realizadas a sus habitantes. Además de realizar el aporte mensual de mayor importancia (1.500 pesos sobre un total de 8.000$)$ entre todos los contribuyentes, la colaboración de Agropecuaria Sanandrés comprendió la compra de una cámara de videovigilancia para la entrada del pueblo y la instalación de una garita para reparo de un sereno contratado por la Comuna. El objeto de esta comisión de seguridad era, en primer lugar, recaudar dinero para costear gastos de combustible y mantenimiento de los vehículos policiales, y para pagar un sereno nocturno. Como explicaba el comisario del pueblo:

Cuando se creó el consejo de seguridad, se colocaron las cámaras y un dispositivo de seguridad que es esto [me muestra un dispositivo semejante a un pendrive, pero de mayor tamaño]. En distintos puntos estratégicos del pueblo y de la zona rural hay postes con un dispositivo similar donde el personal [policial] cuando pasa a recorrer, lo introduce, queda registrado y es un control para que el personal recorra sobre todo durante el horario nocturno y asimismo el personal se siente controlado. A su vez, yo tengo un sistema en la computadora donde me registra el horario y las veces que pasó el personal por ahí [Entrevista $16 / 01 / 2012]$.

De esta manera, todas las instituciones del pueblo quedaban integradas en un sistema de control más o menos explícito: en la Comuna se ejerció un control directo bajo la dirección Pedro Sanandrés; la biblioteca pública, refundada por iniciativa del mismo Sanandrés, recibe la mayor subvención de su empresa; 
la fuerza policial pública es controlada por una "comisión de seguridad" cuyo mayor contribuyente es Agropecuaria Sanandrés, y por último, en la escuela, construida y habilitada por obra de los dueños de esta empresa, se implementan talleres de "formación en valores" brindados por fundación con sede en Buenos Aires, cuyas características abordaremos en el próximo apartado. En los términos de De Imaz (1964), el grupo corresponde a una élite real, es decir, a "un grupo de individuos que concertadamente conduce a la comunidad, la dirige en vista a la obtención de determinados fines, al alcance de ciertos logros, se rige por marcos normativos más o menos similares" y cuya existencia "se determina por los hechos" (p. 236). Ha sido por obra de esta conducción que la élite ha logrado conservar el territorio en un estado de relativo equilibrio social, donde las fuerzas y los grupos antagónicos han sido sistemáticamente expulsados o se les impidió establecerse de manera definitiva en el mismo (por ejemplo, los colonos "revolucionarios" mencionados más arriba), y las resistencias, si bien nunca resueltas de manera definitiva, serán gestionadas a través del dispositivo de los talleres, tal como veremos en el próximo apartado.

\section{LOS TALLERES DE LA FUNDACIÓN}

De la mano de una fundación con sede en Buenos Aires, desde 2009 se implementaban talleres de "formación en valores". Las temáticas desarrolladas en los mismos se presentaban como orientadas al "mejoramiento de personas" y focalizaban el ámbito de los "valores" del individuo como el epicentro a partir del cual generar un "cambio social y cultural" (director comercial de la fundación, registro de campo 4/03/2010). De manera que, iniciado con los empleados de las empresas o los docentes de una escuela por ejemplo, dicho cambio se pudiera extender al ámbito familiar y laboral de cada uno de los participantes, y de allí a la comunidad en su conjunto.

Si por un lado, mientras observaba las instancias de implementación de los talleres, los empleados se manifestaban interesados por las actividades propuestas, la permanencia prolongada en Pueblo Sanandrés reveló que la participación en los talleres se vinculaba a una "obligación" hacia los dueños de la empresa, en los términos de una respuesta moral: no ir al taller era "quedar mal".

Durante 2010, algunos empleados habían manifestado su desacuerdo con los despidos de dos compañeros a través de la amenaza de ausencia a los talleres; utilizaron la resistencia a participar de ese espacio como un instrumento de protesta. En 2012, la situación había cambiado, los empleados manifestaban una resistencia hacia los talleres ya no ligada a una protesta puntual, sino generalizada. Por un lado, los empleados encontraban contradicciones entre los contenidos desarrollados en los talleres y las relaciones laborales que vivían cotidianamente. Estas contradicciones comenzaron a construir una concepción de esos espacios como "falsos", en el sentido de que mostraban algo que no se correspondía con "el día a día" y por ello ya "no valía la pena participar" (Peón, entrevista 3/02/2012). Por otro lado, las condiciones en las que se realizaban los talleres (cierre de la planta y paro de todas las actividades para permitir la participación de la plantilla completa de empleados) ahora resultaban penalizantes: si se dejaba de trabajar durante toda la mañana para participar de los talleres, el trabajo urgente debía realizarse después del horario laboral sin que ello significase un pago extra.

La "obligación" de la participación a los talleres se constituía a partir de un elemento material que era la firma de la asistencia en planillas, y de un elemento simbólico que era la asociación entre la ausencia y una forma de insubordinación al poder. En efecto, al preguntar a los peones por qué seguían asistiendo a los talleres si no les interesaba o no les convenía, insistían sobre el hecho de que "Sanandrés se enoja si no vas" o "quedás mal". Consideraban que ausentarse de los talleres era un "acto de rebeldía" ante aquello que los dueños de la empresa consideraban bueno o correcto, como explicaba esta empleada de la estancia:

Te dicen: “Tenés que ir, tenés que ir, tenés que ir porque... [habla en voz baja, como en secreto] porque Sanandrés se va a enojar" (...) es como un acto de rebeldía no ir. Yo siempre que pude iba, pero a veces cuando tenés gente no podés por más que quieras ¡no vas a dejar todo tirado allá! después quién va a hacer tu trabajo, nadie. Pero a mí me gustan las reuniones, me 
gustan cuando no me obligan... y sí, a quién le gusta cuando te dicen: ¡comete eso! Te lo tragás y no lo disfrutás! [Entrevista 26/01/2012].

Siguiendo la distinción de Scott (2000) entre discurso público y oculto, si por un lado existía un discurso ("me gustan", "te sirven mucho", etc.) y un comportamiento (la asistencia) públicos en torno a los talleres, que mostraban la adhesión a los valores allí promovidos, por otro lado, los empleados eran críticos respecto a la falsedad de lo que en esos "escenarios" se actuaba. Esas críticas se hacían explícitas (adquirían estatus público) ante situaciones de conflictividad, y mostraban -en línea con lo afirmado por Scott (2000, p. 92)tanto la solidaridad puesta en juego en la base subordinada ("nosotros los de abajo"), como la necesidad del conflicto para permitir su emergencia (los despidos de los compañeros). Un empleado de la planta de silos de 24 años de edad, hablando en voz baja hasta casi susurrar por momentos, relataba al respecto:

El tema es que vos vas a los talleres y hablan de compañerismo, de ayudarse, de diálogo, de comunicación y todo eso. Vos salís de ahí adentro y chau, no se habló de nada. Ahí adentro sí, aparenta una cosa, aportan todo... La palabra justa sería: falsedad. Eso es lo que es: falsedad. (...) se habla mucho de respeto y no hay respeto para nada. (...) Los chicos en el trabajo por ahí dicen: “¿Y dónde está lo que se habló en el taller? (...) eso viene más de arriba que de abajo, porque nosotros los de abajo nos conocemos todos... [Entrevista 03/02/2012].

Sin embargo, no asistir a los talleres equivalía a perder el visto bueno de la dirección, y los empleados tenían certeza sobre las consecuencias que esto podía acarrear en el momento en que ellos necesitaran recurrir a los beneficios dados por integrar el sistema de relaciones de patronazgo. La ausencia podía implicar salir de ese sistema de relaciones; de esta manera, los talleres se articulaban con la lógica de patronazgo conformando un sistema moral, como antes mencionábamos.

Pero no sólo se trataba, como explicaban los peones, de un cálculo de beneficios que en última instancia hacía que "te lo tragues". Durante las observaciones en 2010 y 2011 relevé que los talleres efectivamente funcionaban: las personas participaban activamente, se divertían y competían con entusiasmo en las pruebas, tal como lo demostraba el material fotográfico y las expresiones registradas en el campo, durante y luego de los talleres, incluso cuando antes de comenzar hubieran expresado lo contrario. Entonces, ¿cómo funcionaban y qué eran los talleres?

Una primer característica de los talleres era la introducción de dinámicas inhibitorias y prescripciones morales en relación con posibles comportamientos de los empleados, a través de los ejercicios/juegos propuestos por quienes coordinaban los talleres: "al que no le gusta ahí tiene la tranquera"; "no hagan chiquilinadas del tipo 'aumentarles el sueldo a los de tal sector', vamos a jugar en serio"(Registro de campo 27/04/2010). No obstante la advertencia, cuando uno de los peones de campo "jugaba" a ser personal de la administración y dijo que lo primero que haría sería aumentar el sueldo a todos los empleados, quien dirigía el taller (también llamado "facilitador”) exclamó “ése se quedó sin laburo, fue lo último que dijo y se quedó sin laburo". Todos se rieron. Durante otro ejercicio que trataba sobre la "gestión de la negativa” (decir que no ante una demanda que no se puede satisfacer), el facilitador introdujo pautas de conducta ligadas al consumo de alcohol y de marihuana: "cuando le digo que no al porro o al vasito de tinto de más, no le digo 'no' a la persona” (Registro de campo 27/04/2010).

Los empleados aprendían las reglas del juego, en el que una demanda colectiva, como el aumento salarial, no estaba permitida (no era "jugar en serio") e incluso causaba gracia. El reclamo salarial colectivo quedaba así resignificado como chiste que todos entendían. En efecto, si por un lado todos podían solicitar "ayuda" al presidente de la empresa en el marco del sistema de relaciones de patronazgo, por otro, nadie se atrevía a pedir un aumento de sueldo, ni siquiera los cuadros, como ellos mismos reconocían. Así, jugar en los talleres era un aprendizaje de las reglas del juego en el marco de la empresa: se aprendía sobre los comportamientos valorados, los permitidos y los reprobados.

Una segunda característica era la movilización de la dimensión afectiva de las personas durante el despliegue de los ejercicios reflexivos, la toma de la palabra y el contacto (dialógico/discursivo, pero también corporal de acuerdo a lo exigido para la realización de algunas actividades) entre los miembros de un 
equipo de trabajo. Durante mis observaciones registré distintos momentos de alto contenido emotivo y exteriorización de situaciones de la vida privada de las personas que generaban la explicitación de angustia, tristeza, desesperación, felicidad, entre otras emociones. Un facilitador de la fundación reconstruía un particular momento en el que la dimensión afectiva de la persona, solicitada por las ejercitaciones en los talleres, respondía de manera adecuada reforzando el sentido de pertenencia de un empleado a la empresa para la cual trabajaba:

Me acuerdo un caso, estábamos en un pueblito a $150 \mathrm{~km}$ de San Juan que se llama Los Berros. Ahí dinamitan para la estación
de cal. Y había un pobre hombre, digo pobre hombre porque estaba ahí perdido... con una mano que creo que me la apoyaba a
mí y no me podía parar iporque era un gigante! Y él dinamitaba, o sea, su trabajo era estar en la montaña con dinamita. Se me
acercó cuando terminó el taller y yo dije: "iđqué querrá este señor?!", porque aparte ¡la cara curtida...! Yo dije: éste me lincha,
me usa a mí de dinamita... ii Y se me pone a llorar!! (...) me decía: no, porque tuve la oportunidad de pensar que me valoran,
que la empresa me dio la oportunidad para hablar y compartir lo que me pasa y lo que le pasa a mis compañeros” [Entrevista
17/03/2010].

Al recuperar la centralidad de la persona como portadora de afectos que comprenden intereses, motivaciones, sentidos de la vida, relaciones sentimentales y sociales, y también frustraciones, penas, prescripciones morales, etc., los espacios de los talleres generan una "equivalencia humana" de los asistentes, dado que "somos todos seres humanos, desde el presidente de la compañía hasta el último operario" (Facilitador, registro de campo 17/03/2010).

Los espacio-tiempo de los talleres podían así pensarse como escenarios unificadores donde se interpreta la suspensión de las relaciones jerárquicas: al operario que transcurre sus días en medio de las montañas sanjuaninas colocando la dinamita para extraer cales le es revelada su "igualdad" con el empleado administrativo que trabaja en una oficina acondicionada, con el gerente general que tiene su oficina en Buenos Aires y decide sus salarios y los ritmos de trabajo, y con el facilitador del taller -a quien no obstante, no se le escapaban las inscripciones en el cuerpo de las asimetrías sociales ("la mano de gigante", "la cara curtida" por el trabajo en la montaña) y hasta le provocaban cierto temor (“iéste me lincha!”)-. Estos escenarios de igualación, al involucrar la afectividad de las personas y no su posición productiva como fuerza de trabajo, producen liberación, crean lazos afectivos y de deuda, manifestado en el sentido del agradecimiento (tal como muestran varios testimonios de participantes) por la "ganancia" que ellos perciben para sí, pero que es generada por quien contrata los talleres.

En efecto, este último aspecto constituye una tercer característica de los talleres: estos espacios generados por la empresa aparecían como un don, como un "regalo de la empresa" a sus trabajadores, que indicaba el interés y la "valoración de la persona" más allá de sus aptitudes laborales. En palabras de un colaborador de la fundación:

La gente encuentra un espacio donde puede expresarse, donde siente que la empresa le regaló tres horas de su vida, para tratar temas que no los van a llevar a la empresa: los van a llevar a su vida, a la persona, a la parroquia, al club, a su equipo de fútbol, a todos los ámbitos donde ellos se relacionan. No queda sólo en el trabajo, eso es lo importante [Entrevista 17/03/2010].

El mecanismo/dinámica del taller hacía que los empleados se escuchen a sí mismos, ellos eran pronunciados, en sus propios términos, por el facilitador del taller, quien retomaba sus palabras. Al mismo tiempo, el facilitador era quien representaba a la empresa, pues era ésta quien lo contrataba. Al reconocer sus términos y expresarlos como propios, el empleador generaba una ganancia simbólica de la que se apropiaban los empleados: desde el punto de vista del facilitador, ellos ganaban humanidad, eran humanizados por y para la empresa,"se sienten personas”. Pero también, al escucharse desde la posición de poder (la del facilitador) ganan la "imagen” del poder, es decir, su falsificación (Debord, 2002).

Para terminar, en cuanto a la organización de los talleres para el resto de los habitantes de la comunidad (docentes y alumnos de escuela, empleados de la comuna, de la biblioteca, esposas de empleados, etc.), la misma ponía en evidencia una dirección empresarial estratégica a mediano-largo plazo a partir de 
la cual se formaban futuros colaboradores, proveedores o simplemente vecinos de acuerdo a valores funcionales a la reproducción del modelo de producción y del orden social. El director de la escuela, por ejemplo, confirmó que la implementación de los talleres había surgido desde la propuesta de los dueños de la empresa, cuyo "compromiso" estaba ligado a la preocupación por "mejorar la sociedad", eran concebidos como intrínsecamente beneficiosos para quienes participaban, por tanto, "necesarios", así como también "replicables"(Entrevista 27/04/2010). En este sentido, los docentes, por sus propias competencias profesionales, eran un grupo estratégico que hacía posible replicar la experiencia de los talleres con sus alumnos. Otro ejemplo lo constituyen los talleres destinados a las esposas de los empleados. Durante mis observaciones, ellas explicitaban sus relaciones con la familia Sanandrés a lo largo del tiempo, mientras que, quienes no poseían tales referencias escuchaban con atención respetuosa. La invitación a participar de los talleres que se realizaban en la estancia se revelaba como un signo de exclusividad para las mujeres y constituía una prueba de cercanía a la familia Sanandrés, un privilegio de compartir los espacios y el prestigio de la élite.

La familia Sanandrés utilizaba su diferencial de estatus social para garantizar la participación a las instancias de formación donde se abordan contenidos en función de los valores funcionales a la reproducción del modelo agroproductivo que sostenía su posición de poder en el territorio. Este aspecto surgía del análisis de los contenidos de los talleres.

Durante una de las jornadas que observé, las actividades que se desarrollaron ligaban la noción de "profesionalismo" con la de "innovación" y la "adaptación a los cambios". Se proyectaron fotos y un video sobre las transformaciones tecnológicas en la actividad agrícola a través del tiempo. Las imágenes del pasado (alambrado, ganado, arado, pequeñas parcelas cultivadas, trabajadores con herramientas manuales, etc.) se ligaban a una mayor cantidad de trabajo por persona: "se trabajaba mucho más", "se trabajaba de sol a sol”, "era muy sacrificado", mientras que las imágenes del presente (grandes máquinas de siembra/cosecha, amplias superficies cultivadas, trabajadores con computadoras, etc.) eran presentadas en el marco de una tendencia evolutiva natural hacia el progreso, donde el "profesionalismo" se presentaba como la capacidad de adaptación a los cambios: "Cada vez hay más cambios, más tecnología y uno tiene que ir afrontando esos cambios (...). Adaptarse a los cambios es profesional. Es fundamental para seguir creciendo". Contrariamente, la posibilidad de resistirse a los cambios reflejaba un comportamiento improductivo, poco útil para la persona: "Las cosas cambian aunque no nos gusten, así que mientras vos te quejás las cosas siguen cambiando". El taller culminó con una frase "para reflexionar" que implicaba un posicionamiento con respecto a la innovación, la frase era de Eric Hoffer: "En tiempos de cambio, los aprendices heredarán la tierra, mientras que los sabelotodo se encontrarán perfectamente equipados para un mundo que ya no existe" (Registro de campo $18 / 08 / 2010)$.

Estos contenidos eran coherentes con la visión de los dueños de la empresa y acordados con la fundación que implementaba los talleres, en cuanto un énfasis especial estaba puesto en aquello que estos actores llamaban "la cultura del trabajo" como antítesis de una "cultura general del facilismo", tal como afirma el gerente general de la empresa, miembro de la familia Sanandrés:

Agropecuaria Sanandrés es una empresa familiar de más de 150 años que no es fácil de ver en la Argentina y que está basada fundamentalmente en los valores: en la confianza, en la unión, en el compromiso, en las ganas de hacer. Y cuando aparece algo que trabaja en lo que es valores siempre te genera un atractivo, ¿no? (...) El desafío es muy exigente, porque hay que subsistir para tratar de modificar la cultura. Hoy la cultura en general, o lo que se fomenta desde otros ámbitos es el facilismo, que las cosas no te cuesten, que cuanto más rápido mejor, vivir en el spot, nada a mediano plazo y todo ya [Entrevista 27/04/2010].

Esta cultura general presentaba el gran desafío de ser modificada a partir de enseñar a "discernir entre el bien y el mal", capacidad derivada directamente del acceso a una "buena educación" que los pobres podían suplir a partir de la formación brindada por los talleres. El testimonio del gerente de producción -hijo del presidente de Agropecuaria Sanandrés- ilustra de manera ejemplar este aspecto:

En Argentina como en el mundo, se han perdido muchísimos valores, lo ves ¿Y dónde afecta más eso? en las clases más indigentes, en las clases más pobres, porque el pobre tipo no tiene la capacidad, o tiene un pensamiento, una orientación 
distinta. No pudieron tener la educación, no accedieron a la educación, entonces esas personas son mucho más vulnerables [Y] a nosotros nos da una satisfacción enorme que puedan discernir entre el bien y el mal de ciertas cosas (...) Las pobres personas que hoy, suponete, tienen un trabajo razonable, sueldo todos los meses, donde pueden tener una plata de más (...) hay que ver de qué forma a esos que tienen un ingreso económico mensual en el tiempo sostenido, de qué forma ese ingreso lo pueden usar bien, de buena forma: que guarde plata, que se compre una casa, que se compren un lavarropas, que se compren una televisión, que se compre la computadora, que pueda usarlo de buena forma [Entrevista 27/04/2010].

Para estos actores, un "cambio cultural” era necesario en la medida en que reconocían valores antagónicos (facilismo/ganas de hacer, vivir en el spot/compromiso, consumismo/educación, etc.) y se proponían revertir esas oposiciones, educando a sus empleados para que "se den cuenta" de cuáles son "buenos" y cuáles "malos" valores.

El estudio de los talleres revela que el centro del ejercicio del poder no yace en la efectividad del control, del disciplinamiento (éstos serían sus efectos), sino en la producción de sujetos conscientes de sí mismos que eligen libremente "entregar" su vida al capital, en el marco de la reflexividad permitida por el taller. La visión de la esposa del gerente administrativo resume esta articulación entre disciplinamiento, coerción, construcción de pertenencia a un grupo socialyla devolución de los dones en el plano moral:

Si vos encuestás la gente que trabaja ahí vos te vas a encontrar con un factor que es la conducta en cuanto a horarios, responsabilidad... La gente que trabaja ahí tenemos conductas similares. Lo hemos charlado miles de veces. Decimos: "nosotros somos un regimiento, un regimiento aparte", (...) por los horarios, por las conductas, por la forma de hacer: hacés una casa, viajás, formás una familia, tratás que los chicos estudien lo máximo posible, de lo que les guste, pero que estudien, que se incorporen a la sociedad, a distintas comisiones, que trabajen por el pueblo, esos son factores que vos ves en común entre los que trabajamos ahí, pero es porque los imponen. (...) Para mí somos una gran familia, todos los que trabajamos ahí.

(...) Nosotros nos brindamos y ellos nos abrieron las puertas. Entonces es como que les debés la vida [Entrevista 20/01/2012].

Los talleres son espacios privilegiados donde se conducen las conciencias. La resignificación de la participación a los talleres como una adhesión a aquello que la élite dominante considera un "buen comportamiento" permite conectar estos rasgos con la producción de "un sujeto subjetivado por la extracción de verdad que se le impone" (Foucault, 2009, p. 219). Los talleres son dispositivos de extracción de verdad, "verdad de interioridad, verdad oculta del alma a través de la cual se ejercerá el poder del pastor y la obediencia (...) y pasará la economía de los méritos y deméritos" (p. 218). El mecanismo de los talleres extrae verdad que se vuelve conciencia colectiva y que es susceptible de ser "direccionada”, "conducida”. Así, en el corazón del capitalismo contemporáneo encontramos reactualizados los procedimientos del pastorado como "economía de las almas" (pp. 222-223).

\section{MORAL, PODER Y DESIGUALDADES SOCIALES PERSISTENTES}

Hemos descripto como una empresa agroexportadora se garantiza una base social en relativo equilibrio que sostiene y reproduce su posición de poder en el territorio. Vimos que los tres mecanismos principales del ejercicio del poder son: la incorporación de los empleados en un sistema de relaciones de patronazgo, el control de las instituciones comunitarias y la implementación de talleres en valores para empleados y sus esposas, docentes y alumnos de escuelas públicas, empleados de la Comuna y de la biblioteca pública, entre otras instituciones. La caracterización de estos tres mecanismos ha permitido restituir el modo en que persisten desigualdades a lo largo del tiempo, institucionalizando el par categorial rico-bueno / pobre-digno.

El análisis del patronazgo y los dispositivos de disciplinamiento de la fuerza de trabajo implementados en Agropecuaria Sanandrés muestra que la fuerza que obliga a devolver los dones (las ayudas económicas, la protección sanitaria, la invitación a participar de los talleres, etc.) en términos morales no resuelve simplemente la cuestión de la continuidad del lazo social (Mauss, 2009). Dicha obligación emerge, en primer lugar, de la condición previa de despojamiento y miseria de los asalariados provenientes de Santiago del Estero y, por lo tanto, la fuerza que obliga resulta de una coerción de tipo material. Para el caso de los cuadros 
y los empleados técnicos oriundos de la zona, vimos cómo también operaba una necesidad material como la necesidad de la vivienda en el momento de la constitución de una familia. Este trabajo destacó cómo la situación social de partida de cada actor definía el tipo de bien intercambiado: el acceso a los terrenos centrales para los cuadros, los periféricos para los peones estables; financiamiento de estudios universitarios para hijos de los cuadros, terciarios para hijos de empleados o peones jóvenes. De esta manera, el tipo de don ofrecido contribuía a mantener la posición de los actores en la escala social, y permitía desplazamientos paulatinos y controlados. En segundo lugar, la obligación de devolver remite a la construcción afectiva de las personas: sentimientos de empatía, de identificación, y también de culpa ante la posibilidad decepcionar a quien da. Así, la fuerza que obliga a devolver los dones posee tanto un elemento material como uno afectivo y constituye el motor de la generación y regeneración del clima moral de la comunidad estudiada.

Las relaciones de patronazgo que la empresa sostiene posibilitan la persistencia de un sistema de relaciones de dominación y explotación de la fuerza de trabajo, y generan un clima moral en el que, desde la perspectiva de los subordinados a dicho sistema, el patrón es un "buen rico". Es decir, un poseedor de recursos que, desde una posición de superioridad moral, sin tener la obligación de hacerlo, brinda ayuda y protección, distribuye una parte -no importa lo mínima que sea- de su excedente en la forma de dones. Por su parte, en la visión de los actores dominantes en el sistema de relaciones que describimos, los pobres son merecedores de la bondad y la nobleza de los patrones si son trabajadores y si adhieren al universo de valores morales de la élite que conciernen una determinada visión de la familia, del trabajo, de la responsabilidad social de cada uno. Adherir y sostener estos valores hace a la dignidad del pobre: los hace "pobres meritorios" (Villarespe Reyes, 2002; Grignon y Passeron, 1991), merecedores, dignos.

En relación con los talleres para los empleados de la empresa, subrayamos su construcción como espacios donde se activan mecanismos de disciplinamiento que colaboran con una gestión eficaz del proceso productivo y controlan las demandas colectivas. Asimismo, los talleres colaboran en la superación de conflictos a través de esa participación en un escenario común de juego, contacto y comunicación. En contrapartida, la resistencia a la participación de los talleres de la fundación operaba como expresión del conflicto entre los actores que, aun si lograba resolverse en una jornada de taller, volvía a aparecer en las siguientes como una forma de actualización de la tensión social. La dinámica analizada de expresión y resolución de conflictos en el marco de los talleres no implica que los contrastes con la moral de los dueños de la empresa (no por acaso el lugar donde esa tensión se expresaba era el dispositivo de "formación en valores") y las disputas que emergen del ejercicio del poder no vuelvan a aparecer en otro contexto y por otras razones.

Pero lo que aparece como un sentido fuerte de los talleres es que constituyen un efectivo dispositivo de legitimación del universo de valores morales que encarna la familia Sanandrés: desde "afuera", desde Buenos Aires (por la sede de la fundación), como símbolo de lo diverso y lo opuesto al campo, hace llegar el mismo mensaje que los empleados escuchan de sus jefes y de los dueños de la empresa, por otra voz autorizada.

Los talleres construyen sentidos colectivamente, homogeneizan valores según los esquemas normativos de la élite, fijan los límites entre lo que está bien y lo que está mal, y reducen el horizonte de lo posible, presentando a los subordinados (sean empleados de la empresa o de una institución cualquiera del pueblo) un panorama global de adhesión al orden en que se hallan insertos. Son, en definitiva, espacios sociales de práctica material de una determinada visión del mundo y de las cosas, funcionales a la élite dominante. Por ello, no sorprende que los talleres sean, al mismo tiempo, la caja de resonancia de la resistencia a la dominación, es decir, el lugar donde llevar el conflicto y la crítica al poder, del estado oculto al estado público.

Los tres mecanismos de ejercicio del poder analizados, ponen en evidencia que no se trata de un proceso de comunicación de valores de carácter emotivo, como el supuesto por la dominación carismática (Weber, 2012) específicamente irracional, extraña a toda regla, extraña a la economía, sino de un proceso de regulación racional-moral que toma los afectos y la dirección de la conciencia como el anclaje último del proceso de interiorización de la racionalidad capitalista en las personas. Lo que se espera, como sostienen Bolstanki y Chiapello (2010, p. 151), es "un compromiso total (...), que se entreguen -como suele decirse- a su trabajo, 
haciendo posible así una instrumentalización de los seres humanos precisamente en aquello que los hace propiamente humanos", sus afectos, su sentido moral y del honor, su creatividad.

El capitalismo contemporáneo, en el marco del cual el modelo de agronegocios desarrolla su matriz socioproductiva, exige un alto nivel de compromiso con la acumulación que debe poder arraigarse en la construcción afectiva las personas y desde allí, debe poder devenir una fuente de entusiasmo. Este trabajo sobre una élite rural que adopta el modelo productivo en el que una actividad tradicional como la agricultura se ha vuelto un "negocio" global, muestra cómo el capitalismo contemporáneo desplaza la clave de la acumulación del capital del incremento de la productividad a la gestión moral-afectiva, tanto de su personal como de la comunidad social en la que se haya inserta, desde donde puede direccionar las conciencias hacia la intensificación y la reproducción de los procesos de acumulación de la renta.

\section{REFERENCIAS}

Auyero, J. (2004). Clientelismo politico. Las caras ocultas. Buenos Aires: Capital intelectual.

Azcuy Ameghino, E. (2000). Las reformas económicas neoliberales y el sector agropecuario pampeano (1991-1999). Ciclos, 10(20), 191-219.

Balsa, J. J. (2006). El Desvanecimiento del mundo chacarero. Transformaciones sociales en la agricultura bonaerense, 1937-1988. Bernal: Universidad Nacional de Quilmes Editorial.

Barsky, O. y Gelman, J. (2009). Historia del agro argentino. Desde la conquista hasta comienzos del siglo XXI. Buenos Aires: Sudamericana.

Bolstanki, L. y Chiapello, E. (2010). El nuevo espiritu del capitalismo. Madrid: Akal ediciones.

Deambrosi, N. (2012). Análisis de la dinámica urbano-rural a partir de un estudio de caso sobre trabajo ladrillero en el sudeste santiagueño. Question, 1(36), 127-140.

Debord, G.-E. (2002). La sociedad del espectáculo. Madrid: Editora Nacional.

De Imaz, J. L. (1964). Los que mandan. Buenos Aires: EUDEBA

Desalvo, A. (2013). Migraciones estacionales: el caso de los trabajadores santiagueños en el despanojado de maíz (2009-2012). Trabajo y Sociedad, XVII(22), pp. 37-66.

Flammini, M. A. (2001). Algunas reflexiones sobre los cambios económico-sociales del agro pampeano en el siglo XX. Mundo agrario, 1(2), s.p.

Foucault, M. (2009). Seguridad, territorio, población. Buenos Aires: FCE.

Garriga Zucal, J. (2005). Amigos y no tan amigos. Los integrantes de una hinchada de fútbol y sus relaciones personales. Cuadernos del IDES, 7, s.p.

Gellner, E. (1985). Patronos y clientes. En E. Gellner y otros, Patronos y Clientes en las sociedades mediterráneas (pp. 9-16). Madrid:Ediciones Jucar Universidad.

Gras, C. y Hernández, V. (2016). Radiografía del nuevo campo argentino. Del terrateniente al empresario transnacional. Buenos Aires: Siglo XXI.

Grignon, C. y Passeron, J-L. (1991). Lo Culto y lo Popular. Miserabilismo y Populismo en Sociología y en Literatura. Buenos Aires: Nueva Visión.

Hora, R. (2005a). La burguesía terrateniente. Argentina 1810-1945. Buenos Aires: Capital intelectual.

Hora, R. (2005b). Los terratenientes de la pampa Argentina. Una historia social y politica, 1860-1945. Buenos Aires: Siglo XXI.

Hora, R. (2010). Historia económica de la Argentina en el siglo XIX. Buenos Aires: Siglo XXI / Fundación OSDE.

Mastrangelo, A. V. y Deambrosi, N. (2011). Trabajadores y campesinos. Análisis sobe la inserción social como trabajadores de pequeños propietarios de un paraje rural del sureste santiagueño. En A. V. Mastrangelo y V. Trpin (comps.), Entre chacras y plantaciones. Trabajo rural y territorio en producciones que Argentina exporta (pp. 225-251). Buenos Aires: CICCUS. 
Mastrangelo, A. V y Trpin, V. (2013). Trabajo rural en producciones que Argentina exporta. Una síntesis de características relevadas en estudios etnográficos recientes.VII Congreso Latinoamericano de Estudios del Trabajo. El Trabajo en el Siglo XXI. Cambios, impactos y perspectivas. Sao Paulo, Asociación Lationamericana de Estudios del Trabajo.

Mauss, M. (1979). Ensayo sobre el don. Razón y forma del cambio en las sociedades primitivas. En Sociología y Antropologia (pp. 153-263). Madrid: Tecnos.

Miguez, E. J. (1986). La expansión agraria de la Pampa húmeda (1850-1914). Tendencias recientes de su análisis histórico. Anuario IEHS, 1, 89-119.

Moreno Luzón, J. (1994). Propiedad agraria y poder en la Europa contemporánea, Hispania, 54, 557-577.

Murmis, M. y Murmis, M. R. (2011). El caso de Argentina, en Acaparamiento de tierras. Estudios de 17países de América Latina y el Caribe, Oficina regional de la FAO para América Latina y el Caribe, pp. 1-42. Disponible en http:// www.rlc.fao.org/fileadmin/content/events/semtierras/acaparamiento.pdf (consultado en abril 2013).

Neiman, G. (2009). Estudio exploratorio y propuesta metodológica sobre trabajadores agrarios temporarios migrantes. Informe final de consultoría. Buenos Aires, Ministerio de Economía y Producción/Secretaría de Agricultura, Ganadería, Pesca y Alimentos/PROINDER.

Pucciarelli, A. R. (1986). El capitalismo agrario pampeano 1880-1930. Buenos Aires: Hyspamérica.

Pucciarelli, A. R. (1996). El poder material de la burguesía terrateniente. Notas sobre la evolución de la noción de latifundio (Primera parte 1900/1950), Cuadernos del CISH, 1(1). Disponible en: http://www.memoria.fahce.u nlp.edu.ar/art_revistas/pr.2490/pr.2490.pdf (consultado en diciembre 2017).

Quaranta, G. y Blanco, M. (2012). Formas actuales de circulación y conformación de patrones migratorios de hogares rurales en la provincia de Santiago del Estero, Argentina. Ruris, 6(1), 127-158.

Sabato, H. (1989). Capitalismo y ganadería en Buenos Aires. La fiebre del lanar, 1850-1890. Buenos Aires: Editorial Sudamericana.

Scobie, J. R. (1968). Revolución en las pampas. Historia social del trigo argentino 1860-1910. Buenos Aires: Solar/ Hachette.

Scott, J. (1985). ¿Patronazgo o explotación?. En E. Gellner y otros, Patronos y Clientes en las sociedades mediterráneas (pp. 35-61). Madrid: Ediciones Jucar Universidad.

Scott, J. C. (2000). Los dominados y el arte de la resistencia. México: Ediciones Era.

Tasso, A. y Zurita, C. (2013). Aves de paso: Los trabajadores estacionales de Santiago del Estero. Trabajo y Sociedad, 21, 33-47.

Tilly, C. (2002). La desigualdad persistente. Buenos Aires: Manantial.

Villarespe Reyes, V. (2002). Pobreza: Teoría e historia. México: Casa Juan Pablos, UNAM.

Volkind, P. (2010). Mano de obra familiar y trabajo asalariado. Reflexiones en torno al desarrollo del capitalismo en el agro pampeano, 1895-1914. Los casos de Pergamino y Rojas. Documentos del CIEA, 5.

Vommaro, G. y Combes, H. (2016). El clientelismo politico. Desde 1950 hasta nuestros días. Buenos Aires: Siglo XXI.

Weber, M. (2012). Economia y Sociedad. Buenos Aires: FCE.

\section{Notas}

1 El presente artículo está basado en la ponencia presentada en las III Jornadas IEALC (UBA) "Valores y disciplinamiento en la ruralidad contemporánea. Estudio de una empresa agroexportadora y su pequeña comunidad de influencia en el sur santafecino". Buenos Aires, septiembre 2016.

2 En su clásica tipología de las explotaciones agropecuarias para el período 1880-1930, Pucciarelli (1986) considera empresas capitalistas a las explotaciones con más de 200 has, maquinaria y mano de obra asalariada.

3 Como señalan Mastrangelo y Trpin (2013, p. 9), “este tipo de intermediación es una de las manipulaciones de las condiciones legales vigentes para la contratación de trabajadores en el medio rural. (...) reduce la protección legal dada al empleo rural $[\mathrm{y}]$ desdibuja el carácter periódico de los ciclos anuales de trabajo rural, inhibiendo el cobro de seguro 
Mundo Agrario, abril 2018, vol. 19, n 40, e075. ISSN 1515-5994

de desempleo que correspondería si todos fuesen contratados como asalariados rurales permanentes o no (tal como lo estipulan las leyes nacionales 25.191 y 22.248, Res. RENATRE 14/2004).” 